\title{
Eradication of Helicobacter pylori may improve dyspepsia in the elderly for the long term
}

\author{
Ikko Tanaka', Shoko Ono ${ }^{2 *}$, Yoshihiko Shimoda', Masaki Inoue', Sayoko Kinowaki ${ }^{1}$, Momoko Tsuda ${ }^{3}$, \\ Masayoshi Ono ${ }^{1}$, Keiko Yamamoto ${ }^{4}$, Yuichi Shimizu ${ }^{4}$, Mototsugu Kato ${ }^{3}$ and Naoya Sakamoto ${ }^{1}$
}

\begin{abstract}
Background: Therapy for eradication of Helicobacter pylori (H. pylori) improves symptoms of H. pylori-associated dyspepsia (HPD), but the effects of eradication in elderly patients are unclear. The aim of our study was to investigate dyspepsia symptoms and long-term effects of eradication in elderly patients.

Methods: This retrospective study included 496 patients who received H. pylori eradication therapy. The patients were divided into a group of elderly patients (group $\mathrm{E}: \geqq 65$ years old) and a group of non-elderly patients (group $\mathrm{N}:<65$ years old). Abdominal symptoms were evaluated using a questionnaire about abdominal symptoms before eradication and after eradication (1-2 months and more than one year). Dyspepsia was defined as a score of 4 points or more for at least one of 4 items (postprandial fullness, early satiety, epigastric pain, and hunger pain). Improvement of symptoms was defined on the basis of changes in Global Overall Systems scores.

Results: There were no differences in abdominal symptoms before eradication between the two groups. Successful eradication improved symptoms in patients with dyspepsia within 2 months (in 75.6\% (56/74) of the patients in group N and in 64.5\% (20/31) of the patients in group E). The questionnaire showed that $80 \%$ (32/40) of the patients in group $\mathrm{N}$ and $60 \%$ (12/20) of the patients in group $\mathrm{E}$ had long-term relief of dyspepsia. The scores for abdominal symptoms in group $\mathrm{E}$ continued to improve for a mean period of 54.8 months after eradication.
\end{abstract}

Conclusions: Eradication of $H$. pylori age-independently improved dyspepsia symptoms for the long term.

Keywords: Dyspepsia, Helicobacter pylori, Eradication therapy, The elderly

\section{Background}

Functional dyspepsia (FD) is defined in the ROMA IV criteria as one or more of the following symptoms persisting for the past 3 months with symptom onset at least 6 months ago: postprandial fullness, early satiation, epigastric pain and epigastric burning [1]. Helicobacter pylori (H. pylori) infection is often associated with

\footnotetext{
*Correspondence: onosho@med.hokudai.ac.jp

${ }^{2}$ Department of Gastroenterology, Hokkaido University Hospital,

Sapporo, Hokkaido, Japan

Full list of author information is available at the end of the article
}

dyspepsia symptoms, and it has been reported that eradication of $H$. pylori improved the symptoms [2-4]. In the Kyoto Global Consensus Report in 2015, it was stated that all $H$. pylori-positive individuals worldwide should receive eradication therapy [5]. Furthermore, H. pyloriassociated dyspepsia (HPD) is defined in that report as sustained symptomatic relief for 6 to 12 months after eradication, because the symptomatic gain takes at least 6 months to become significant over no eradication and this has been attributed to the time it takes for gastritis to recover [5]. 
In Japan, $H$. pylori infection is one of the major infections, especially in elderly people [6]. Mamori et al. reported that the rate of successful eradication of $H$. pylori in first-line therapy was lower in patients less than 50 years of age than in patients aged over 50 years [7]. However, Kobayashi et al. reported that age did not affect the efficacy or safety of eradication therapy [8]. Pilotto et al. also reported that outcomes of eradication and incidence of adverse events for the elderly were the same as those on non-elderly people $[9,10]$. However, there have been few reports on the effect of $H$. pylori eradication on dyspepsia symptoms in elderly people. In this study, we evaluated the outcomes of $H$. pylori eradication therapy and followed the long-term effect on dyspepsia symptoms in elderly patients.

\section{Methods}

\section{Patients}

Consecutive patients who visited our $H$. pylori-specific out-patient unit and received eradication therapy during the period from January 2009 to December 2017 were retrospectively analyzed. Esophagogastroduodenoscopy revealed no active gastric diseases before eradication in any of the patients. We divided the patients into two groups according to age: an elderly group (group E) of patients who were 65 years of age or older and a non-elderly group (group $\mathrm{N}$ ) of the patients who were less than 65 years of age. The study was approved by the Ethics Committee of Hokkaido University Hospital (Approval Number 018-0367). All patients provided written informed consent.

\section{H. pylori test}

Before eradication, both a ${ }^{13} \mathrm{C}$-urea breath test (UBT) $\left(\right.$ Ubit $^{\circledR}$, Otsuka Pharmaceutical, Tokyo, Japan) and one or more other $H$. pylori tests (rapid urease test, serological and urinary anti-H. pylori IgG antibody, culture and microscopic examination) were used. Generally, patients in whom one of the tests was positive were defined as positive for H. pylori.

Successful eradication was confirmed using the UBT at 1 to 2 months after the completion of eradication treatment. When the values of UBT were negative before eradication and when the values of UBT were weakly positive ( 2.5 to $5.0 \%$, cut-off value: $2.5 \%$ ) after eradication, we confirmed the results of other tests.

\section{Eradication regimen}

The prescribed regimens during the study period are summarized in Additional file 1: Table S1. Vonoprazan (VPZ) has been available since March 2015 in our institution and proton-pump inhibitors (PPIs) were changed to VPZ after it became available.

\section{Evaluation of upper gastrointestinal symptoms}

A questionnaire with a scale from 1 (no problem) to 7 (very severe problem) consisting of 17 items covering Global Overall Systems (GOS) and Gastrointestinal Symptom Rating Scale was used [11, 12]. The questionnaire was filled out by each patient before the UBT. Patients who had a score of 4 points or more for at least one of 4 items (postprandial fullness, early satiety, epigastric pain, and hunger pain) were defined as patients with dyspepsia before eradication (1st questionnaire). Improvement of dyspepsia was defined as a decrease in the maximum score of abdominal symptoms before eradication by more than 2 points and each GOS item after eradication therapy being less than 3 points. For evaluation of upper gastrointestinal (GI) symptoms, that GOS questionnaires are simple and valid outcome measurements to assess the symptoms of FD according to the severity of the following eight symptoms: epigastric pain, heartburn, acid reflux, stomach discomfort, nausea, belching, early satiety and distention $[10,13$, 14]. The 2nd questionnaire was given to patients on the day of judgement.

For evaluation of the long-term effects $H$. pylori eradication on dyspepsia symptoms, the 3rd questionnaire was given to patients with defined dyspepsia before eradication for whom more than 1 year had passed after successful eradication. HPD was defined as sustained dyspepsia relief for more than 1 year after successful eradication and it was confirmed by the 3rd questionnaire.

\section{Measured outcome parameters}

The primary endpoint was long-term improvement in the GOS score after successful $H$. pylori eradication in elderly patients with dyspepsia. Secondary endpoints were successful eradication rates, adverse events, and shortterm and long-term improvements of each GOS item in groups $\mathrm{E}$ and $\mathrm{N}$.

Analysis of $H$. pylori eradication efficacy was performed on an intention-to-treat (ITT) basis. Compliance with therapy and adverse events were determined by a questionnaire at the time of judgement of $H$. pylori eradication.

\section{Sample size}

Based on an expected 25\% difference in long-term improvement of dyspepsia between young patients (50\%) and elderly patients (25\%) using G power $(\alpha=0.05$, $\beta=0.2$ ) from previous our data, we estimated that a sample size of 132 patients (66 patients in each group) would be sufficient to demonstrate a significant difference. 


\section{Statistical analysis}

Mean values were calculated for continuous variables and percentages were calculated for categorical data. Categorical data were compared using Fisher's exact test and numerical data were compared using Student's $t$-test. A $P$ value of $<0.05$ in each analysis was considered statistically significant.

\section{Results}

\section{Outcomes of $\boldsymbol{H}$. pylori eradication therapy}

A total of 496 patients received $H$. pylori eradication therapy during the study period. Fifty-nine patients who did not meet our criteria for diagnosis of $H$. pylori infection were excluded, and finally a total of 437 patients including 275 patients in group $\mathrm{N}$ and 162 patients in group $\mathrm{E}$ were analyzed. Flow diagram for treatment and characteristics of the patients are shown in Fig. 1 and Additional file 1: Table S2. ITT eradication rates were $84.4 \%(232 / 275)$ in group $\mathrm{N}$ and $74.7 \%(121 / 162)$ in group $\mathrm{E}$, and there was a significant difference between the two groups $(P=0.02)$. According to the number of eradications, only the success rate for the 3rd-line eradication in group $\mathrm{E}$ was significantly lower than that in group N (59.7\% vs $76.5 \%, P=0.03)$. There was no significant

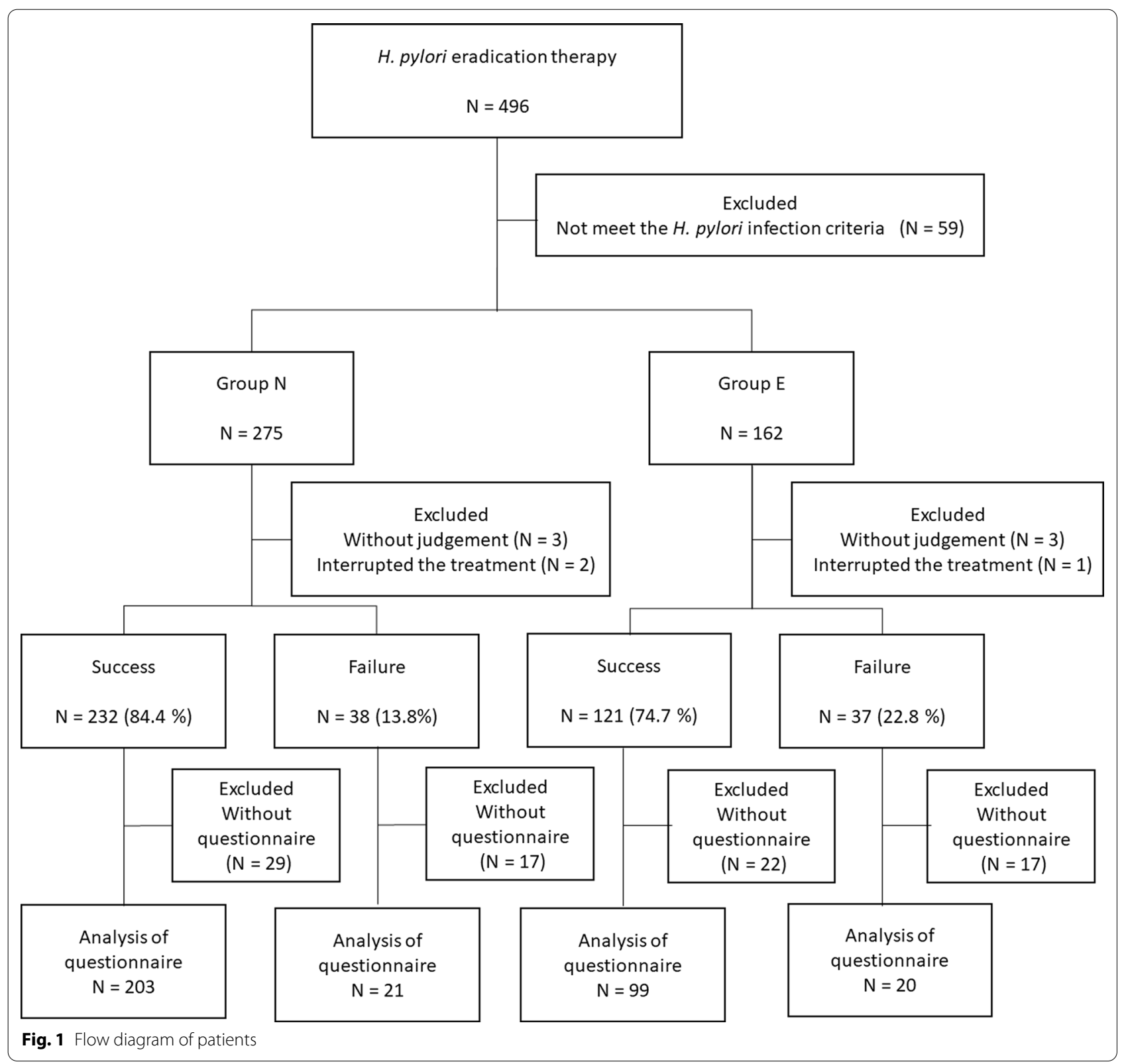


difference in adverse events associated with eradication therapy between the two groups.

\section{Upper GI symptoms before and just after eradication therapy}

Eighty-five participants did not fill out the questionnaire, and data for 343 patients including 302 patients in whom eradication was successful and 41 patients in whom eradication therapy failed were analyzed (Fig. 1).

In the patients in whom eradication therapy failed, there was no significant difference in GOS scores before and after eradication therapy: $1.80 \pm 1.11$ before and $1.82 \pm 0.80$ after in group $\mathrm{E}(\mathrm{n}=20)(P=0.94)$ and $2.13 \pm 1.15$ before and $1.84 \pm 0.94$ after in group $\mathrm{N}$ $(\mathrm{n}=21)(P=0.06)$.

In the patients in whom $H$. pylori was eradicated, there were no significant differences between the two groups in total GOS score and score of each item before eradication. Successful eradication significantly improved upper GI symptom (Additional file 1: Table S3).

According to our definition of dyspepsia, 74 (36.5\%) of the patients in group $\mathrm{N}$ and 31 (31.3\%) of the patients in group $\mathrm{E}$ had dyspepsia before eradication. Within 2 months after successful eradication, $75.6 \%(56 / 74)$ of the patients in group $\mathrm{N}$ and $64.5 \%(20 / 31)$ of the patients in group $\mathrm{E}$ had improvement in dyspepsia $(P=0.34)$ (Table 1).

\section{Long-term effects of $H$. pylori eradication on dyspepsia}

We sent the 3rd questionnaire to 105 patients who had been defined as having dyspepsia before eradication and in whom $H$. pylori had been eradicated. Responses to the questionnaire were obtained from 40 patients in group $\mathrm{N}$ and 20 patients in group E. Mean periods from successful eradication to filling out the questionnaire were 61.3 (15-124) months in group $\mathrm{N}$ and 54.8 (12-116) months in group $\mathrm{E}(P=0.51)$ (Table 2$)$.

GOS scores at the time of the 3rd questionnaire were significantly decreased compared to those before eradication in both groups (Fig. 2). Thirty-two patients (80\%) in group $\mathrm{N}$ and 12 patients (60\%) in group $\mathrm{E}$ had longterm improvement after eradication $(P=0.13)$ (Table 2$)$. Short-term and long-term effects of eradication on dyspepsia symptoms were different in $35.0 \%$ of the patients in group $\mathrm{N}$ and $50.0 \%$ of the patients in group $\mathrm{E}$ (Fig. 3).

\section{Discussion}

It has been shown that $H$. pylori eradication therapy is also effective for the elderly [7, 8, 15-17]. However, it has been reported that the prevalence of esophagitis and chronic gastritis and the function of the gastrointestinal tract are different in the elderly than in the non-elderly $[10,18]$. There is no specific recommendation of $H$. pylori for elderly people in the Kyoto Global Consensus Report in 2015 [5]. The risks and benefits of eradication in the elderly, especially for dyspepsia, are unclear. Our study showed that eradication provided long-term relief of dyspepsia symptoms for elderly patients.

Dyspepsia symptoms often occur in $H$. pylori-positive individuals. Shimatani et al. reported that the proportion of patients with dyspeptic symptoms was significantly higher in $H$. pylori-positive patients than in $H$. pylorinegative patients $(28.7 \%$ vs $6.5 \%)$ [19]. Kawamura et al. also reported that $46.3 \%$ of $H$. pylori-positive patients had dyspepsia symptoms [20]. Approximately 30\% of our patients had dyspepsia symptoms, and the percentage is similar to that in previous studies.

Table 1 Dyspepsia before and after successful eradication

\begin{tabular}{|c|c|c|c|}
\hline & Group N $(n=203)$ & Group E (n=99) & $P$ \\
\hline Mean age at $H$. pylori eradication, years \pm SD & $51.4 \pm 9.9$ & $70.6 \pm 4.85$ & - \\
\hline Sex (men/women) & $87 / 116$ & $34 / 65$ & 0.17 \\
\hline Patients with dyspepsia before eradication, n (\%) & $74(36.5)$ & $31(31.3)$ & 0.44 \\
\hline Improvement in dyspepsia after eradication, n (\%) & $56 / 74(75.6)$ & $20 / 31(64.5)$ & 0.34 \\
\hline
\end{tabular}

Table 2 Long-term follow-up of dyspepsia symptoms after successful eradication

\begin{tabular}{|c|c|c|}
\hline & Group N $(n=40)$ & Group E $(n=20)$ \\
\hline Sex (men/women), n & $17 / 23$ & $9 / 11$ \\
\hline Mean age at $H$. pylori eradication, years (range) & $52.4(17-64)$ & $70.0(65-76)$ \\
\hline Mean period between eradication and 3rd questionnaires, months (range) & $61.3(15-124)$ & $54.8(12-116)$ \\
\hline Patients who met the definition of H. pylori-associated dyspepsia, n (\%) & $32(80)$ & $12(60)$ \\
\hline
\end{tabular}




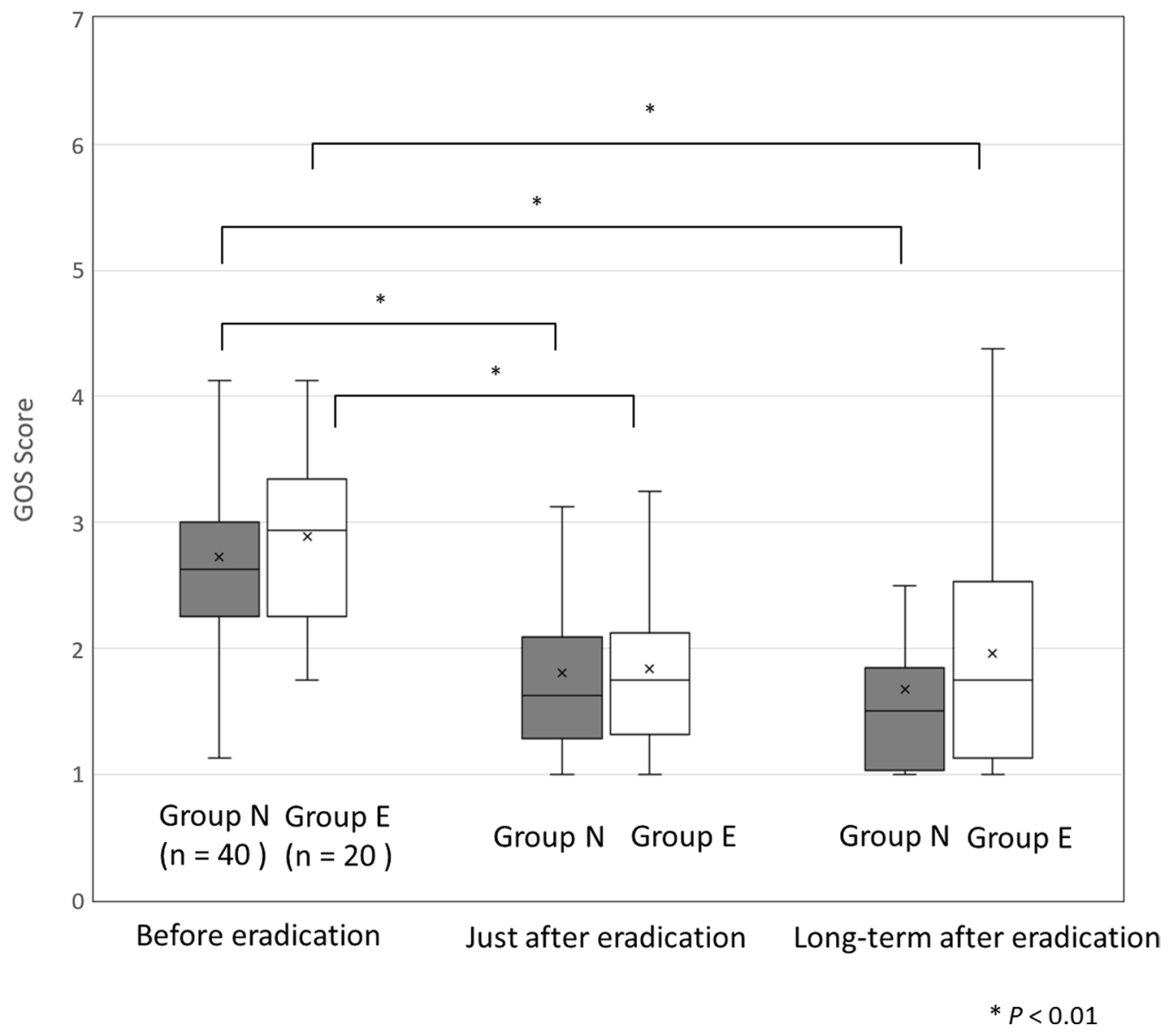

Fig. 2 Changes in GOS scores based on questionnaires. There was no significant difference in GOS score between the two groups at any time point: $2.72 \pm 0.93$ in group $N$ and $2.88 \pm 0.67$ in group E before eradication $(P=0.48), 1.83 \pm 0.87$ in group $N$ and $1.84 \pm 0.61$ in group $E$ just after eradication (at $1-2$ months) $(P=0.88), 1.68 \pm 0.88$ in group $N$ and $1.95 \pm 1.00$ in group $E$ in the long term $(P=0.28)$. In the long term after successful eradication, GOS score was significantly decreased compared to that before eradication in both groups $(P<0.01)$

It has been reported that $H$. pylori eradication therapy improved dyspepsia symptoms in $24-53 \%$ of patients [2, 21-24]. In our study, dyspepsia symptoms after successful eradication improved in about $73 \%$ of the patients in the long term, and the percentage of patients was slightly higher that in the previous studies (Fig. 3). Unfortunately, the definitions of improvement of dyspepsia were different in some studies, and further research is needed to compare the symptoms using the same methods at the same timing after eradication.

Tsuda et al. reported that a questionnaire within 2 months after $H$. pylori eradication might be useful for diagnosis in $70 \%$ of patients with HPD [25]. Similarly, questionnaires in the short term after eradication predicted HPD in $60 \%$ of elderly patients. However, the symptoms in $40 \%$ of the patients with dyspepsia changed in the long term and HPD could not be predicted. According to Kyoto Global Consensus Report, it is necessary to follow symptoms for more than 6 months after successful eradication to determine HPD as was indicated by our results [5]. The strength of our study was that the median time of the 3rd questionnaire was more than 4 years after eradication, and we were able to evaluate long-term effects of eradication on HPD.

H. pylori infection may cause dyspeptic symptoms through several mechanisms such as alterations of gastric acid secretion and persistent and active inflammation of the gastric mucosa [26]. Also, H. pylori may cause delays in gastric emptying and antral gastric secretion that are related to dyspeptic symptoms [27, 28]. There has been no report on a difference in the mechanisms between the elderly and non-elderly. Since $H$. pylori eradication often improves inflammation of the mucosa, acid secretion and gastric emptying often improve [29-31].

Our results showed that there was no significant difference in the improvement of dyspepsia between the elderly and non-elderly patients, though the elderly patients tended to have only slight improvement or 


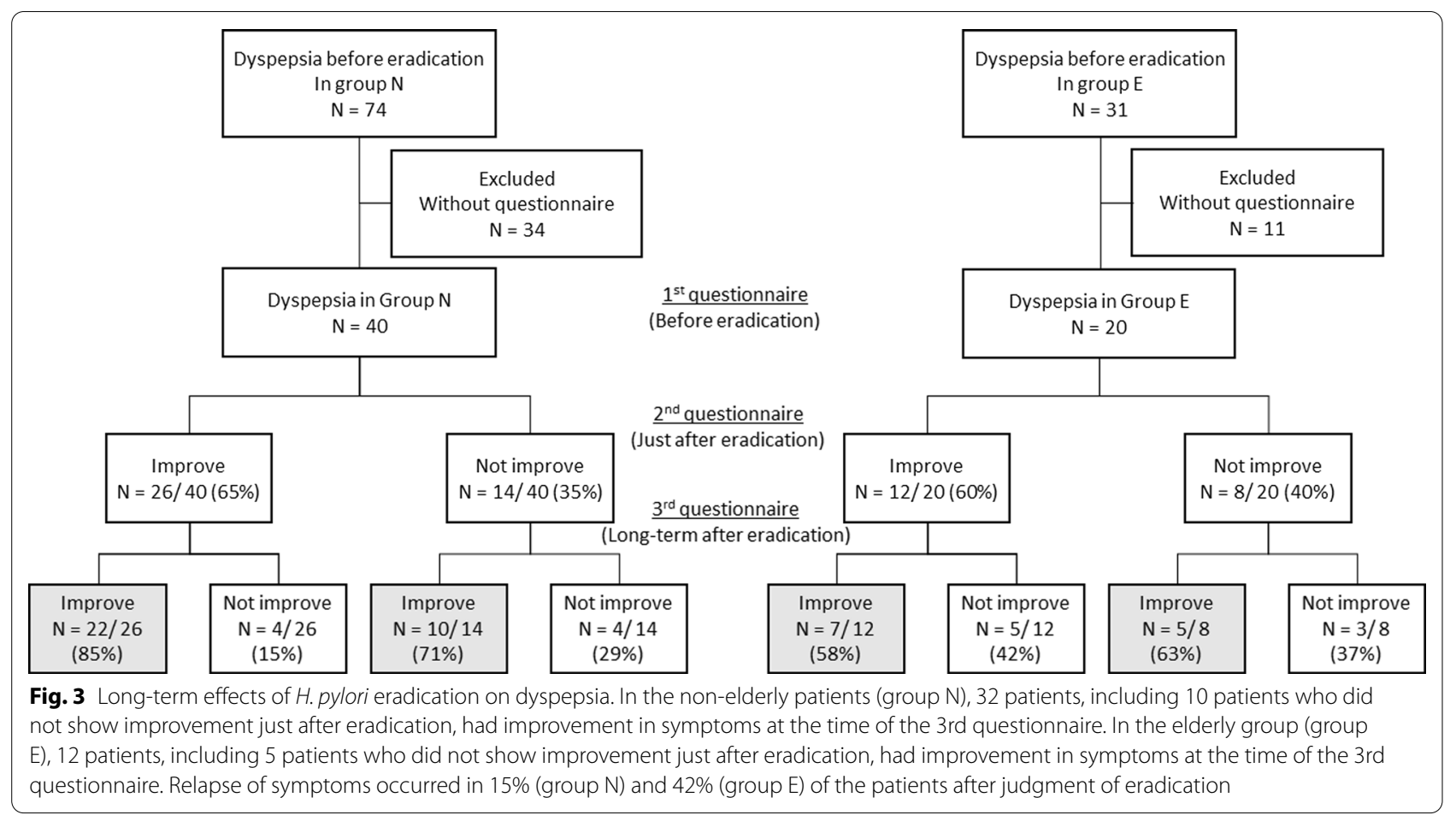

relapse of dyspepsia symptoms. Atrophic gastritis, function of the gastrointestinal tract, medication, psychiatric illnesses, lifestyle with eating and exercise, and stress may be cause of such a difference $[10,18,32,33]$.

There have been a few studies on outcomes of eradication therapy for the elderly, but the outcomes investigated in those studies were for 1st-line and 2nd-line therapies $[7,8,15,34]$. In our study, there was a significant difference in eradication rates only in the 3rd-line therapy. There were no significant differences in rates of eradication using PPIs and VPZ, and Kusunoki et al. and Nishida et al. reported that the effect of VPZ was unclear in elderly patients $[15,34]$. Resistance to clarithromycin might be the main reason for failure of 3rd-line therapy, but that was unfortunately not checked in our subjects $[35,36]$. Also, adverse events of eradication therapy are one of the concerns for the elderly. We have not experienced serious adverse events in eradication therapy, but there has been a report of death in an elderly patient [37]. Therefore, it is necessary to pay attention to drug interaction, hepatorenal function and co-morbidities in eradication, especially for the elderly.

The present study has several limitations. This study was a retrospective study with a small sample size conducted at a single institution. Also, antibiotic resistance was not tested. Another limitation is that the 3rd questionnaire survey was carried out as a cross-sectional survey. A study conducted for a period of 7 years after
H. pylori eradication showed a fluctuation in dyspeptic symptoms after $H$. pylori eradication [32]. Therefore, our results may not reflect a lasting improvement effect. Also, this retrospective observational study did not satisfy the expected sample size due to our strict definition of dyspepsia and the poor response rate in the 3rd survey (57\%). Therefore, our results are limited and further study with a large sample size is needed.

\section{Conclusion}

Eradication of H. pylori age-independently improved dyspepsia symptoms. A test and treat strategy for H. pylori may be recommended for elderly patients with dyspepsia symptoms.

\section{Supplementary Information}

The online version contains supplementary material available at https://doi. org/10.1186/s12876-021-02027-6.

Additional file 1. Supplement table 1. Regimens of Helicobacter pylori eradication. Supplement table 2. Characteristics of patients. Supplement table 3. Score of abdominal symptoms before and after successful eradication.

\section{Acknowledgements}

Not applicable.

\section{Authors' contributions}

IT, SO and MK designed the study; IT, SO and MT performed the research; YS, SK, MI, MO, KY and YS analyzed the data; IT, SO and NS wrote the paper; and 
NS revised the manuscript for final submission. All authors read and approved the final manuscript.

\section{Funding}

There is no funding for the study.

\section{Availability of data and materials}

The datasets used and/or analysed during the current study are available from the corresponding author on reasonable request.

\section{Declarations}

\section{Ethics approval and consent to participate}

This study was performed in accordance with the ethical standards detailed in the Declaration of Helsinki. The study was reviewed and approved by the Hokkaido University Hospital Review Board 018-0367. All patients provided written informed consent.

\section{Consent for publication}

Not applicable.

\section{Competing interests}

The authors declare that have no competing interests.

\section{Author details}

${ }^{1}$ Department of Gastroenterology, Hokkaido University Graduate School of Medicine, Sapporo, Hokkaido, Japan. ${ }^{2}$ Department of Gastroenterology, Hokkaido University Hospital, Sapporo, Hokkaido, Japan. ${ }^{3}$ Department of Gastroenterology, National Hospital Organization Hakodate National Hospital, Hakodate, Hokkaido, Japan. ${ }^{4}$ Division of Endoscopy, Hokkaido University Hospital, Sapporo, Hokkaido, Japan.

\section{Received: 15 November 2020 Accepted: 15 November 2021}

\section{Published online: 25 November 2021}

\section{References}

1. Stanghellini V, Chan FK, Hasler WL, et al. Gastroduodenal disorders. Gastroenterology. 2016;150(6):1380-92

2. Du LJ, Chen BR, Kim JJ, Kim S, Shen JH, Dai N. Helicobacter pylori eradication therapy for functional dyspepsia: systematic review and meta-analysis. World J Gastroenterol. 2016;22(12):3486-95.

3. Zhao B, Zhao J, Cheng WF, et al. Efficacy of Helicobacter pylori eradication therapy on functional dyspepsia: a meta-analysis of randomized controlled studies with 12-month follow-up. J Clin Gastroenterol. 2014;48(3):241-7

4. Armstrong D. Helicobacter pylori infection and dyspepsia. Scand J Gastroenterol Suppl. 1996;215:38-47.

5. Sugano K, Tack J, Kuipers EJ, et al. Kyoto global consensus report on Helicobacter pylori gastritis. Gut. 2015;64(9):1353-67.

6. Kamada T, Haruma K, Ito M, et al. Time trends in Helicobacter pylori infection and atrophic gastritis over 40 years in Japan. Helicobacter 2015;20(3):192-8.

7. Mamori S, Higashida A, Kawara F, et al. Age-dependent eradication of Helicobacter pylori in Japanese patients. World J Gastroenterol. 2010;16(33):4176-9.

8. Kobayashi S, Joshita S, Yamamoto C, et al. Efficacy and safety of eradication therapy for elderly patients with helicobacter pylori infection. Medicine. 2019;98(30):e16619.

9. Pilotto A, Franceschi M, Leandro G, et al. Cure of Helicobacter pylori infection in elderly patients: comparison of low versus high doses of clarithromycin in combination with amoxicillin and pantoprazole. Aliment Pharmacol Ther. 2001;15(7):1031-6.

10. Pilotto A, Franceschi M, Leandro G, et al. Influence of Helicobacter pylori infection on severity of oesophagitis and response to therapy in the elderly. Dig Liver Dis. 2002;34(5):328-31.

11. Veldhuyzen van Zanten SJ, Chiba N, Armstrong D, et al. Validation of a 7-point Global Overall Symptom scale to measure the severity of dyspepsia symptoms in clinical trials. Aliment Pharmacol Ther. 2006;23(4):521-29.

12. Svedlund J, Sjodin I, Dotevall G, et al. GSRS-a clinical rating scale for gastrointestinal symptoms in patients with irritable bowel syndrome and peptic ulcer disease. Dig Dis Sci. 1988;33(2):129-34.

13. van Zanten SV, Armstrong D, Chiba N, et al. Esomeprazole 40 mg once a day in patients with functional dyspepsia: the randomized, placebocontrolled "ENTER" trial. Am J Gastroenterol. 2006;101(9):2096-106.

14. Sakurai K, Nagahara A, Inoue K, et al. Efficacy of omeprazole, famotidine, mosapride and teprenone in patients with upper gastrointestinal symptoms: an omeprazole-controlled randomized study (J-FOCUS). BMC Gastroenterol. 2012;12:42.

15. Kusunoki M, Yuki M, Ishitobi $H$, et al. Effect of age on effectiveness of vonoprazan in triple therapy for Helicobacter pylori eradication. Intern Med. 2019;58(11):1549-55.

16. Nishida T, Tsujii Y, Okamoto A, et al. A triple-drug blister-packaged drug with vonoprazan improves first-line eradication of helicobacter pylori in elderly patients: a retrospective propensity score-matched cohort study. Digestion. 2019;66:1-7.

17. Pilotto A, Franceschi M, Leandro G, et al. Efficacy of 7 day lansoprazolebased triple therapy for Helicobacter pylori infection in elderly patients. $J$ Gastroenterol Hepatol. 1999;14(5):468-75.

18. Grassi M, Petraccia L, Mennuni G, et al. Changes, functional disorders, and diseases in the gastrointestinal tract of elderly. Nutr Hosp. 2011;26(4):659-68.

19. Shimatani T, Inoue M, Iwamoto K, et al. Prevalence of Helicobacter pylori infection, endoscopic gastric findings and dyspeptic symptoms among a young Japanese population born in the 1970s. J Gastroenterol Hepatol. 2005:20(9):1352-7.

20. Kawamura Y, Funaki Y, Yoshimine T, et al. Characteristics and predictive factor of Helicobacter pylori-associated functional dyspepsia in Japanese patients. Digestion. 2019;100(4):277-85.

21. Mazzoleni LE, Sander GB, Francesconi CF, et al. Helicobacter pylori eradication in functional dyspepsia: HEROES trial. Arch Intern Med. 2011:171(21):1929-36.

22. Khan MQ. Helicobacter pylori eradication therapy in nonulcer dyspepsia is beneficial. Saudi J Gastroenterol. 2008;14(2):96-100.

23. Allison JE, Hurley LB, Hiatt RA, Levin TR, Ackerson LM, Lieu TA. A randomized controlled trial of test-and-treat strategy for Helicobacter pylori: clinical outcomes and health care costs in a managed care population receiving long-term acid suppression therapy for physician-diagnosed peptic ulcer disease. Arch Intern Med. 2003;163(10):1165-71.

24. Gwee KA, Teng L, Wong RK, Ho KY, Sutedja DS, Yeoh KG. The response of Asian patients with functional dyspepsia to eradication of Helicobacter pylori infection. Eur J Gastroenterol Hepatol. 2009;21(4):417-24.

25. Tsuda M, Kato M, Ono S, et al. Changes of dyspeptic symptom after successful eradication in Helicobacter pylori-associated Dyspepsia. Digestion. 2019;66:1-9.

26. Potamitis GS, Axon AT. Helicobacter pylori and nonmalignant diseases. Helicobacter. 2015;20(Suppl 1):26-9.

27. Suzuki H, Moayyedi P. Helicobacter pylori infection in functional dyspepsia. Nat Rev Gastroenterol Hepatol. 2013;10(3):168-74.

28. Zagari RM, Law GR, Fuccio $L$, et al. Epidemiology of functional dyspepsia and subgroups in the Italian general population: an endoscopic study. Gastroenterology. 2010;138(4):1302-11.

29. Watanabe $\mathrm{H}$, Yamaguchi $\mathrm{N}$, Kuwayama $\mathrm{H}$, et al. Improvement in gastric histology following Helicobacter pylori eradication therapy in Japanese peptic ulcer patients. J Int Med Res. 2003;31(5):362-9.

30. lijima K, Ohara S, Sekine $H$, et al. Changes in gastric acid secretion assayed by endoscopic gastrin test before and after Helicobacter pylori eradication. Gut. 2000;46(1):20-6.

31. Murakami K, Fujioka T, Shiota K, et al. Influence of Helicobacter pylori infection and the effects of its eradication on gastric emptying in nonulcerative dyspepsia. Eur J Gastroenterol Hepatol. 1995;7(Suppl 1):S93-97.

32. di Mario F, Stefani N, Becro ND, et al. Natural course of functional dyspepsia after Helicobacter pylori eradication: a seven-year survey. Dig Dis Sci. 2005;50(12):2286-95

33. Koloski NA, Jones M, Walker MM, Holtmann G, Talley NJ. Functional dyspepsia is associated with lower exercise levels: A population-based study. United Eur Gastroenterol J. 2020;8(5):577-83. 
34. Nishida T, Tsujii Y, Okamoto A, et al. A triple-drug blister-packaged drug with vonoprazan improves first-line eradication of Helicobacter pylori in elderly patients: a retrospective propensity score-matched cohort study Digestion. 2020;101(5):608-14.

35. Graham DY, Shiotani A. New concepts of resistance in the treatment of Helicobacter pylori infections. Nat Clin Pract Gastroenterol Hepatol. 2008;5(6):321-31.

36. Kato M, Ota H, Okuda M, et al. Guidelines for the management of Helicobacter pylori infection in Japan: 2016 Revised Edition. Helicobacter. 2019;24(4):e1297.
37. Nei T, Hagiwara J, Takiguchi T, et al. Fatal fulminant Clostridioides difficile colitis caused by Helicobacter pylori eradication therapy; a case report. J Infect Chemother. 2020;26(3):305-8.

\section{Publisher's Note}

Springer Nature remains neutral with regard to jurisdictional claims in published maps and institutional affiliations.
Ready to submit your research? Choose BMC and benefit from:

- fast, convenient online submission

- thorough peer review by experienced researchers in your field

- rapid publication on acceptance

- support for research data, including large and complex data types

- gold Open Access which fosters wider collaboration and increased citations

- maximum visibility for your research: over $100 \mathrm{M}$ website views per year

At BMC, research is always in progress.

Learn more biomedcentral.com/submissions 